\title{
Effect of Austempering Time on the Microstructure and Carbon Partitioning of Ultrahigh Strength Steel 56NiCrMoV7
}

\author{
Quanshun Luo *, Matthew Kitchen and Shahriar Abubakri (D) \\ Materials and Engineering Research Institute, Sheffield Hallam University, Howard Street, \\ Sheffield S1 1WB, UK; acesmk@exchange.shu.ac.uk (M.K.); acessa1@exchange.shu.ac.uk (S.A.) \\ * Correspondence: q.luo@shu.ac.uk; Tel.: +44-114-2253649
}

Received: 23 May 2017; Accepted: 3 July 2017; Published: 7 July 2017

\begin{abstract}
Ultrahigh strength steel $56 \mathrm{NiCrMoV7}$ was austempered at $270{ }^{\circ} \mathrm{C}$ for different durations in order to investigate the microstructure evolution, carbon partitioning behaviour and hardness property. Detailed microstructure has been characterised using optical microscopy and field emission gun scanning electron microscopy. A newly developed X-ray diffraction method has been employed to dissolve the bainitic/martensitic ferrite phase as two sub-phases of different tetragonal ratios, which provides quantitative analyses of the carbon partitioning between the resultant ferrites and the retained austenite. The results show that, a short-term austempering treatment was in the incubation period of the bainite transformation, which resulted in maximum hardness being equivalent to the oil-quenching treatment. The associated microstructure comprises fine carbide-free martensitic and bainitic ferrites of supersaturated carbon contents as well as carbon-rich retained austenite. In particular, the short-term austempering treatment helped prevent the formation of lengthy martensitic laths as those being found in the microstructure of oil-quenched sample. When the austempering time was increased from 20 to $80 \mathrm{~min}$, progressive decrease of the hardness was associated with the evolution of the microstructure, including progressive coarsening of bainitic ferrite, carbide precipitating inside high-carbon bainitic ferrite and its subsequent decarbonisation.
\end{abstract}

Keywords: ultrahigh strength steel; austempering; carbon partitioning; carbide precipitation; bainitic/martensitic ferrite

\section{Introduction}

Low alloy ultrahigh strength steels are key structural materials for load-bearing components of large vehicles and aircrafts [1-3]. In addition to the conventional strengthening treatments of quenching and tempering $(\mathrm{QT})$ and bainitic salt bathing process, a new treatment has been developed by lowering the salt bath temperature to a level close to, or even lower than, the Ms (martensite starting) temperature [4-10]. The resultant microstructure comprises extremely fine ferrite laths and inter-lath filmy austenite, both having super-saturated carbon contents because of the prohibition of carbide precipitation. Such ferrite based microstructure enables ultrahigh strength properties, e.g., $2.5 \mathrm{GPa}$ of compression strength and 2.3 GPa of ultimate tensile strength. However, such a process needs a very long salt bath time, and concern also arises from the low toughness property [5,6,11].

When an austempering treatment is applied, wherein the austenised steel is firstly soaked for a short period in a salt bath of lower-bainite transformation and is subsequently quenched to room temperature, the resultant microstructure is a mixture of bainite, martensite and retained austenite [3,12-17]. The new heat treatments were reported to bring about higher hardness and strength properties than the QT treatments, while the strengthening mechanisms have not been fully understood up to date. Tomita and co-workers attributed the increased strength properties to several 
factors, including martensite grain refining, due to partitioning of austenite by bainitic ferrite prior to martensite transformation, the predominant role of the major martensite plates, and strain-hardening of the bainitic ferrite, induced by the martensite transformation [18]. These explanations were also adopted by other researchers $[13,16-18]$. However, the contribution of supersaturated carbon to hardening was excluded in this model.

In recent years, increasing attention has been paid on the role of carbon in steel strengthening. Supersaturated carbon is highly involved in several strengthening mechanisms of ultrahigh strength steels, regardless of the transformation kinetics [19-21]. In the transformation from austenite to martensite or bainite, carbon is known to diffuse from newly formed martensite or bainite to the parent austenite. This phenomenon, known as carbon partitioning, has been utilised to develop a novel toughening treatment, i.e., the so-called quenching and partitioning (Q-P) treatment [22-25]. Although carbon partitioning as a general phenomenon was noticed a long time ago [2,26], it is in the Q-P process that the phenomenon was used the first time to control the transformed microstructure [22].

In a recent project, we worked on austempering treatments of a $\mathrm{Cr}-\mathrm{Ni}-\mathrm{Mo}-\mathrm{V}$ alloyed spring steel, which led to superior mechanical properties, including ultimate tensile strength of $2100 \mathrm{MPa}$, yielding strength of $1800 \mathrm{MPa}$ and elongation of $8-10 \%$, along with V-notched Charpy impact toughness of $9-12 \mathrm{~J} / \mathrm{cm}^{2}[27,28]$. This paper reports the microstructure characterisations of a series of austempered samples, with a focus on the carbon partitioning behaviour at various isothermal soaking times.

\section{Experimental}

The sample material was vacuum-re-melted steel and provided as a $50 \mathrm{~mm}$ diameter hot-rolled bar with nominal chemical compositions (in wt \%) of C 0.55, Si 0.30, Mn 0.76, P 0.014, S 0.0037, Ni 1.69, Cr 1.05, Mo 0.50, V 0.08, and Fe in balance. The $\mathrm{A}_{\mathrm{c} 3}, \mathrm{~A}_{\mathrm{c} 1}$ and $\mathrm{M}_{\mathrm{S}}$ temperatures of the steel are estimated to be 780,715 , and $240{ }^{\circ} \mathrm{C}$ respectively, as provided by the steel supplier (Böhler Tool Steel \& High Speed Steel, Oldbury, UK). The bar was cut as block samples of $20 \mathrm{~mm} \times 10 \mathrm{~mm} \times 8 \mathrm{~mm}$ in size for austempering heat treatments. In the heat treatments, the samples were heated in the first salt bath to soak at $850^{\circ} \mathrm{C}$ for $30 \mathrm{~min}$. Then they were moved immediately to the second salt bath to soak at $270{ }^{\circ} \mathrm{C}$ (i.e., $30^{\circ} \mathrm{C}$ above the $\mathrm{M}_{\mathrm{s}}$, at the range of lower bainite transformation) for a selected time before air-cooling to room temperature. The austempering soaking times were selected to be 5, 10, 20, 40 and $80 \mathrm{~min}$.

The austempered samples were mounted, and manually ground to remove a surface layer of about $0.3 \mathrm{~mm}$ in thickness using coarse $\mathrm{SiC}$ abrasive paper (grade 120 \#). Then fine grinding was applied using $\mathrm{SiC}$ abrasive papers of grades 240 and 600 \# for hardness testing. Vickers hardness tests were undertaken at an indenting load of $30 \mathrm{~kg}$. Five indents were made on each sample to calculate the average hardness and the standard deviation. Then following metallographic grinding and polishing, the samples were etched using a $\%$-nital etchant before microstructure characterisations using optical microscopy (OPM, Olympus BX51, Tokyo, Japan), scanning electron microscopy (SEM) and X-ray diffraction (XRD).

A FEI Nova200 field emission gun (FEG, Eindhoven, The Netherlands) SEM was employed, where the field emission gun provides a spatial resolution of $1.8 \mathrm{~nm}$, being sufficient to resolve nano-scale structural features. A X'Pert X-ray diffractometer (PANalytical, Almelo, The Netherlands) with $\mathrm{Cu}-\mathrm{K}_{\alpha}$ radiation (wavelength $\lambda=0.15406 \mathrm{~nm}$ ) was employed in the study. On each sample, five diffraction peaks were acquired under the $\theta-2 \theta$ (Bragg-Brentano) mode, including the austenite peaks $(200)_{\gamma},(220)_{\gamma}$ and (311) $)_{\gamma}$, and the ferrite peaks $(200)_{\alpha}$ and (211) $\alpha$. The obtained diffractions were measured using a self-developed Gaussian peak-fitting technique to determine the peak position $(2 \theta)$, net intensity $(I)$ and broadening width $(\beta)$ (FWHM, the full-width at half maximum) $[27,28]$. These parameters were then used to calculate the volume fraction $\left(V_{\gamma}\right)$ and carbon content $\left(C_{\gamma}\right)$ of retained austenite and the micro-strains $(\varepsilon)$ of both the martensitic and bainitic ferrite and the retained austenite. The equations for the calculations were adapted from literature $[29,30]$. 


$$
\begin{gathered}
V_{\gamma}=I_{\gamma} \times\left(I_{\gamma}+G \times I_{\alpha}\right)^{-1} \\
C_{\gamma}=\left(a_{\gamma}-0.3555\right) / 0.0044 \\
\varepsilon=0.25 \times \beta \times \cos \theta \times \sin \theta^{-1}
\end{gathered}
$$

In Equation (2), $a_{\gamma}$ stands for the austenite lattice parameter, which is an average of three lattice parameter values derived from the $(200)_{\gamma},(220)_{\gamma}$ and $(311)_{\gamma}$ measurements. The $(200)_{\alpha}$ diffraction peak was numerically processed more extensively using a newly developed quantitative method. Details of the new method have been described elsewhere [31]. The new analytical method considers martensite in a hardened medium-carbon steel as a mixture of lath- and plate-martensites, whereas the two martensite sub-phases are known to have different tetragonal ratios because of their different carbon contents.

\section{Results}

\subsection{Hardness Property of Austempered Samples}

Figure 1a shows the effect of austempering time on the hardness property. When a short-time austempering was applied, the steel remained a high level of hardness, being even slightly higher than the as-quenched sample (HV 679). The maximum hardness of HV 716 was measured in the sample that was austempered for $10 \mathrm{~min}$; then, further increased austempering time from 10 to $40 \mathrm{~min}$ resulted in remarkably decreased hardness. Following that, the hardness stabilised in that level when the austempering time was extended to $80 \mathrm{~min}$. These results suggest that a short period of isothermal treatment did not soften the steel, while the steel became substantially softer when the treatment was longer.

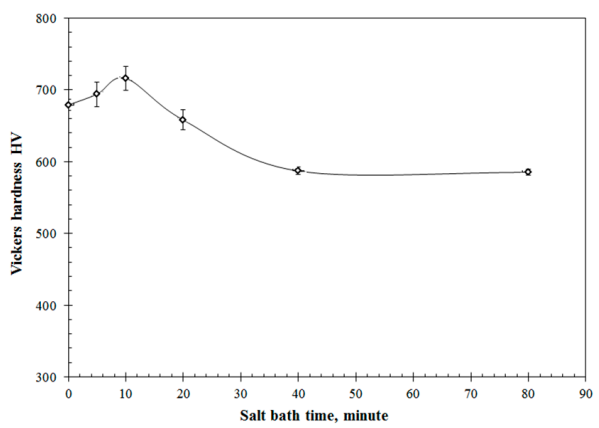

(a)

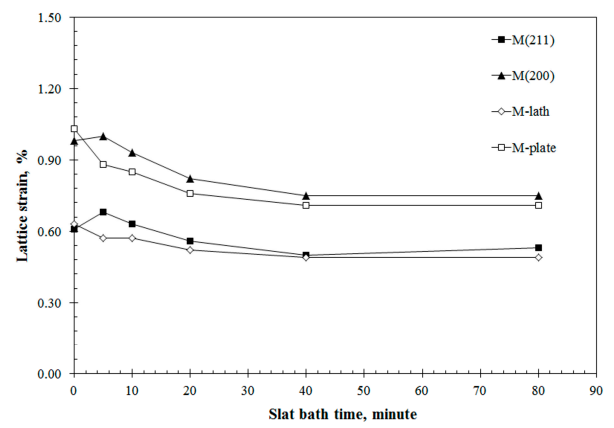

(b)

Figure 1. Effect of austempering time on (a) the hardness property of the sample steel and (b) the lattice strains of the martensitic and bainitic ferrites.

Figure $1 \mathrm{~b}$ illustrates the variation of overall lattice strains of the martensitic and bainitic ferrites as determined by XRD peak broadening analyses. Firstly, both the overall diffraction peaks $(200)_{\alpha}$ and $(211)_{\alpha}$ were analysed to calculate the lattice strains along the $<200>$ and $<211>$ directions. Then by Gaussian separation of the $(200)_{\alpha}$ peak as sub-peaks, the martensitic or bainitic ferrite was considered as two sub-phases having different tetragonal ratios, namely lath martensite $\left(\mathrm{M}_{\text {lath }}\right)$ and plate martensite $\left(\mathrm{M}_{\text {plate }}\right)$ [31]. Consequently the lattice strains of the $\mathrm{M}_{\text {lath }}$ and $\mathrm{M}_{\text {plate }}$ sub-phases can be estimated. The analyses reveal correlation between the hardness property and the lattice strains of the martensitic and bainitic ferrite, which is consistent with the knowledge that martensitic transformation is the predominant hardening mechanism. The strains decrease gradually with increasing austempering time. The calculated strain, consistent with the hardness property, can be attributed to both the recovery of defects and the ferrite decarbonisation as a result of carbide 
precipitation. Moreover, in the ferritic sub-phases, the higher micro-strain values of the $M_{\text {plate }}$ reveal its substantially higher lattice distortion than the $\mathrm{M}_{\text {lath }}$.

\subsection{Microstructure Observed in Optical Microscopy}

In OPM observations, bainitic ferrite was easily recognised as black acicular grains. The OPM images displayed in Figure 2 show variation of the martensitic and bainitic microstructure with increasing austempering time. The oil-quenched sample was known to have predominantly martensitic structure, whereas it also shows some black-etched acicular grains similar to bainite. The black contrast in these acicular grains suggests fine carbide precipitates, which has been confirmed in subsequent SEM observations at higher magnification, to be discussed later in Figure 3. The sample austempered in 5 min exhibits mostly martensitic microstructure, comparable to the oil-quenched sample, as shown in Figure 2a,b. When the austempering time was increased to 10 and $20 \mathrm{~min}$, the steel shows a mixed microstructure of bainite and martensite where the amount of bainite increases with the austempering time, (Figure 2c,d). In Figure 2c,d, the bainite regions exhibit black contrast because of the preferential etching of the bainite grains as compared to the martensite. The bainite and martensite regions are labelled "B" and " $\mathrm{M}$ ", respectively.
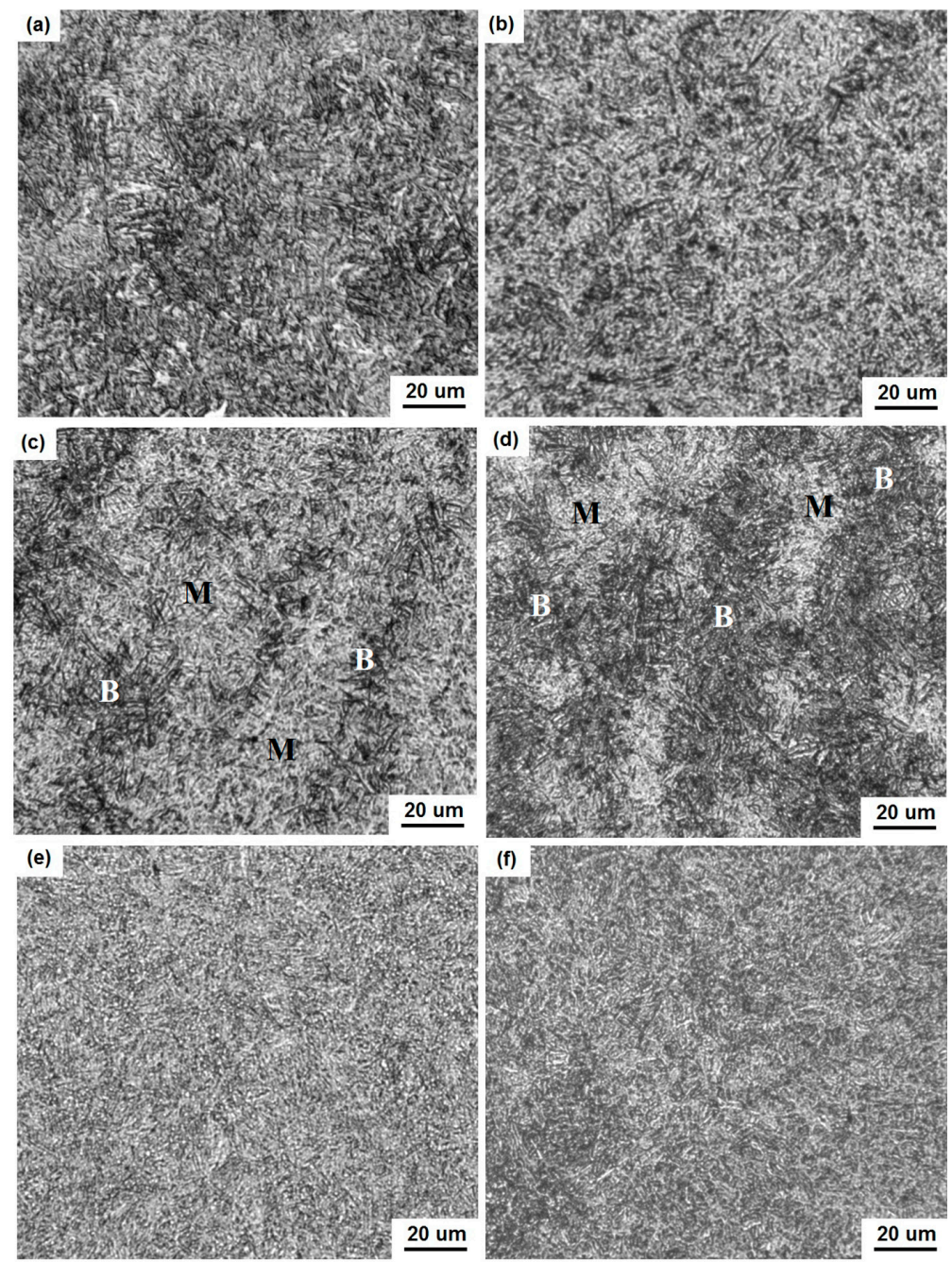

Figure 2. Optical micrographs of samples after $270{ }^{\circ} \mathrm{C}$ austempering treatment for various durations: (a) oil-quenched; (b) $5 \mathrm{~min}$; (c) $10 \mathrm{~min}$; (d) $20 \mathrm{~min}$; (e) $40 \mathrm{~min}$; and (f) $80 \mathrm{~min}$. 
The samples being austempered by 40 and $80 \mathrm{~min}$ are similar to each other and exhibit a relatively homogeneous contrast, because that bainitic transformation had taken place in the whole volume, as shown in Figure 2e,f. The change from heterogeneous to homogeneous microstructure suggests that the bainite transformation was completed in an intermediate time between 20 and $40 \mathrm{~min}$, whereas further soaking after the completion did not give rise to noticeable change in the optical microstructure.

The OPM observations suggest that, bainite transformation did not take place in the initial short period, indicating the existence of a bainitic incubation period, as suggested by other researchers [32-34]. In the current work, noticeable bainite transformation took place after an incubation period of less than $10 \mathrm{~min}$ and, after that, significant austenite to bainite transformation occurred with increasing soaking time.

In addition, the OPM observations also suggest heterogeneous distribution of the bainitic structure. In Figure $2 \mathrm{c}, \mathrm{d}$, the bainite-rich regions exhibits black contrast as compared to the martensite-rich regions, in which initial bainite formed preferentially in the dendritic stems where $\mathrm{C}-\mathrm{Cr}$-Mo contents are lower than the inter-dendritic areas. The structural heterogeneity arose from the dendritic segregation of the as-cast steel. Such segregation was developed in the casting and was retained even after the hot rolling. Similar structural heterogeneity was also reported in other low alloy steels [35].

\subsection{Microstructure Observed in Scanning Electron Microscopy}

In Figure $3 \mathrm{a}, \mathrm{b}$, the microstructures of the $5 \mathrm{~min}$ austempered and oil-quenched samples are compared to each other at low magnification imaging, both showing as a mixture of lath- and plate-shape martensites. In drawing comparisons between Figure $3 a, b$, the martensites of austempered steel are more uniform and also slightly smaller in grain size. The comparison may reveal grain refining by means of the short austempering pre-treatment. Previously, researchers have attributed the grain refining to the increased ferrite nucleation sites [32-35]. They described such short-range motion of carbon atoms in the bainite incubation period as spinodal decomposition, which resulted in nano-scale heterogeneous distribution of carbon atoms to fertilise nucleation of ferrite in the carbon-depletion domains.

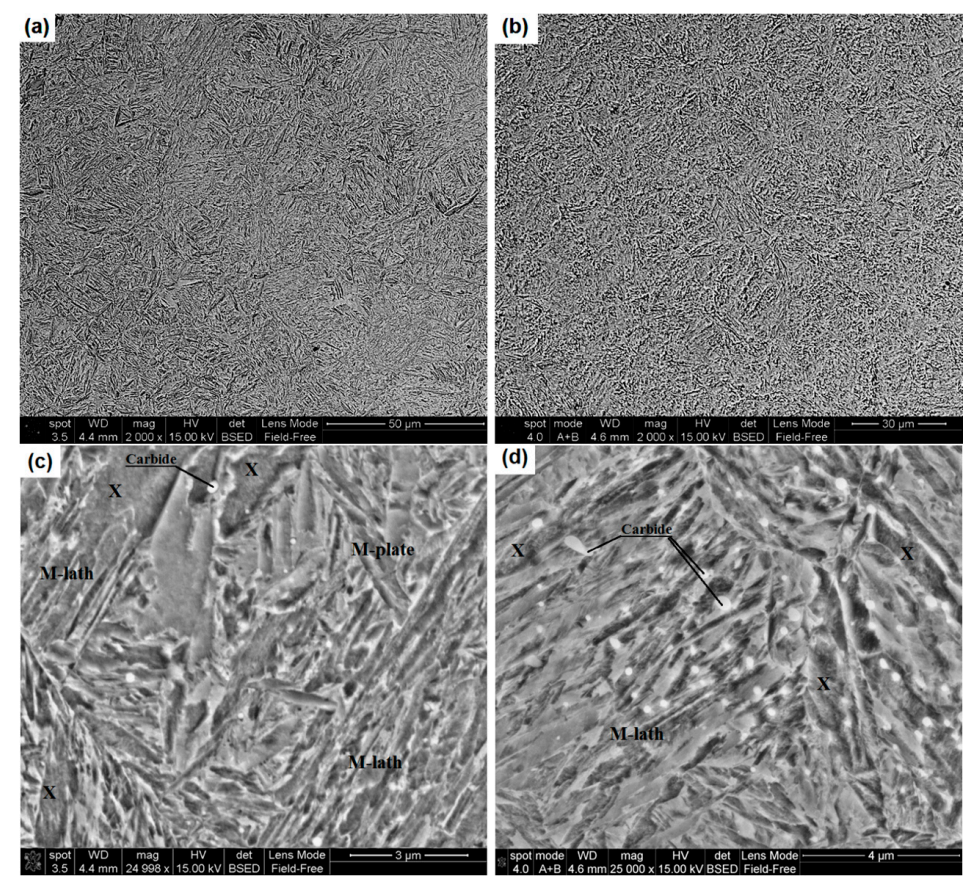

Figure 3. Field emission gun scanning electron microscopy (FEG-SEM) images of $(\mathbf{a}, \mathbf{c})$ the oil-quenched sample and $(\mathbf{b}, \mathbf{d})$ the 5 min austempered sample. 
Details of the microstructure constituents are presented at high magnification in Figure $3 c, d$, in which the lath- and plate-shape martensites are labelled. Observations at higher magnifications showed that, some coarse martensite grains contain extremely fine particles, indicative of carbide precipitation, e.g., in the grains labelled " $X$ ". Such precipitation is more pronounced in the oil-quenched sample, which is shown in Figure 3c. On the other hand, most of the martensite grains of the austempered sample are free from carbide precipitation, as shown in Figure $3 \mathrm{~d}$.

In addition, small quantities of un-dissolved carbide particles can also be observed. At high magnification, these particles have a round shape and disperse heterogeneously in the matrix, as labelled "Carbides" in Figure 3c,d. The presence of un-dissolved carbides was attributed to insufficient decomposition of the cementite grains in the austenisation stage. In the heat treatment, the samples were heated to $850^{\circ} \mathrm{C}$ and kept isothermally at that temperature for $30 \mathrm{~min}$. The holding time was not long enough to have all the cementite carbide grains dissolve in the austenite matrix.

In a set of low-magnification SEM images, Figure 4 illustrates the bainitic grain growth with increasing austempering time. In Figure $4 \mathrm{a}$, the $10 \mathrm{~min}$ treated sample exhibits a heterogeneous distribution of lath- and plate-shape martensite or bainite. The laths are fine and narrow, located mostly in the regions containing un-dissolved nodular carbide particles. In contrast, the rest regions show relatively coarse ferritic leaves, (the lightly etched, labelled " $B$ "). These leaves are believed to be carbide-free bainitic ferrite by comparing them to the grain coarsening and carbide precipitation in similar regions. Nevertheless, the sample still shows fine grain size. Significant grain coarsening happened when the austempering time was increased to 20 and $40 \mathrm{~min}$, as shown in Figure $4 \mathrm{~b}, \mathrm{c}$. In Figure $4 \mathrm{~b}$, the less-etched blocks are mixtures of acicular martensite or bainite and blocky retained austenite (labelled "A"). A few small needle-like ferrite grains (labelled with an arrow) can be found inside a blocky austenite grain, implying fine martensite plates growing inside partitioned austenite, which is consistent with the grain refining mechanism proposed by Tomita [3]. In Figure 4c, bainitic ferrite becomes the dominant structural component in the $40 \mathrm{~min}$ treated sample and the inter-granular austenite has been much less. When the isothermal soaking time was increased to $80 \mathrm{~min}$ in Figure $4 \mathrm{~d}$, the whole image is almost full of bainitic ferrite grains, except for some very narrow inter-lath filmy austenite, as well as un-dissolved carbide particles.
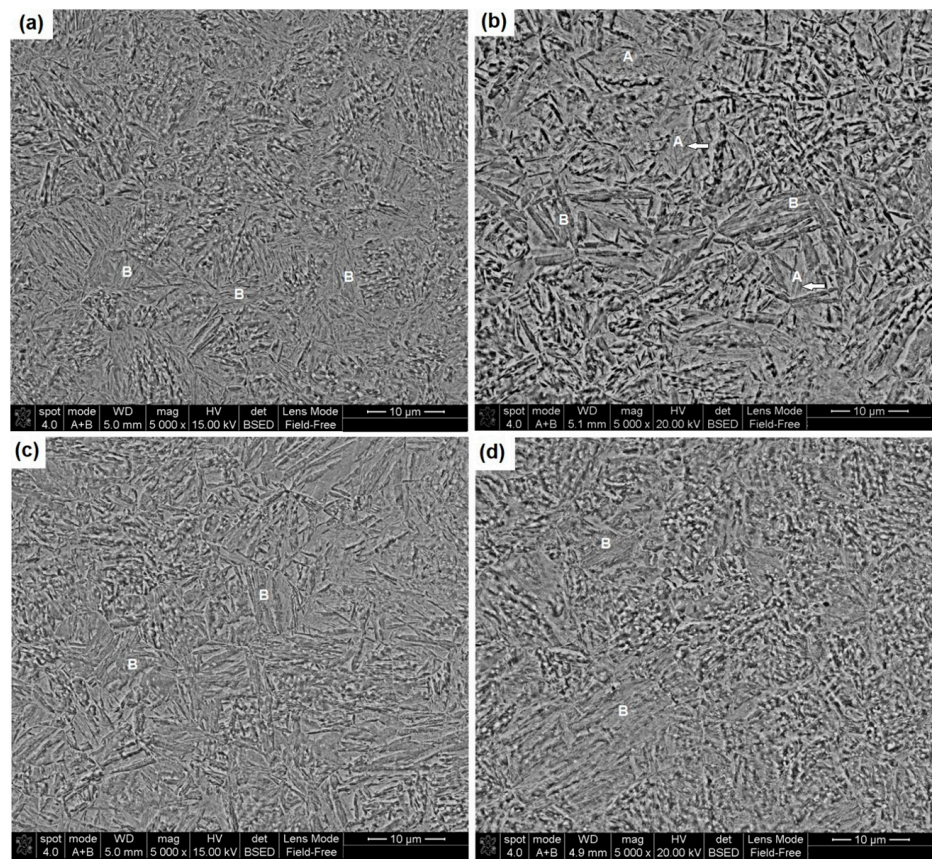

Figure 4. Low-magnification FEG-SEM images of samples austempered for different durations: (a) $10 \mathrm{~min}$; (b) $20 \mathrm{~min}$; (c) $40 \mathrm{~min}$; and (d) $80 \mathrm{~min}$. Note the growth of bainitic ferrite. 
Figure 5 shows evolution of the microstructure at high magnification, wherein one can see the growth of carbide precipitates inside the bainitic ferrite grains. In Figure 5a,b, the 10 and 20 min treated samples show a mixture of bainite (labelled " $\mathrm{B}$ ", containing carbide precipitates) and martensite (labelled " $\mathrm{M}$ ", precipitate-free). In Figure 5c, some bainite grains contain carbide precipitates which are as fine as those shown in Figure $5 b$, whereas others show coarse precipitates. In Figure 5d, the microstructure shows significantly coarsened precipitates. It is believed that, the carbide coarsening followed the diffusion kinetics, i.e., taking place by absorbing carbon atoms from the ferrite matrix. As a result, the carbon content of the ferrite should be gradually lower, leading to decreased micro-straining, as shown in Figure 1b, and decreased lattice tetragoneity. This has been confirmed by the XRD analysis as described below.
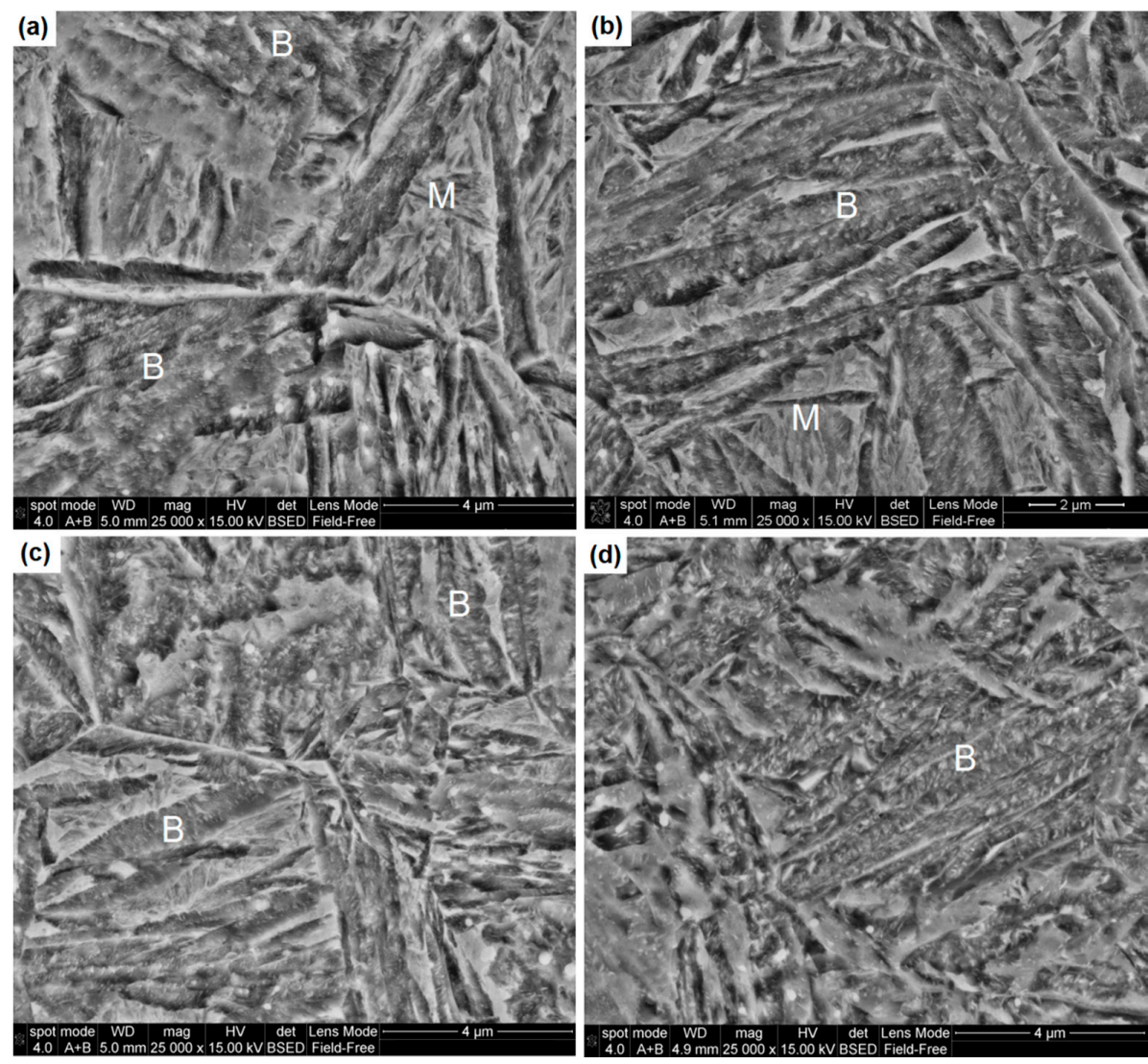

Figure 5. High-magnification FEG-SEM images of samples austempered for different durations: (a) $10 \mathrm{~min}$; (b) $20 \mathrm{~min}$; (c) $40 \mathrm{~min}$; and (d) $80 \mathrm{~min}$. Note the growth of bainitic ferrite.

\subsection{Results of X-ray Diffraction Analyses}

Figure 6 shows the collected diffraction peaks of both the austempered and oil-quenched samples. A quick comparative view reveals that the oil-quenched sample exhibits the maximum peak broadening, whereas the peaks of the austempered samples become increasingly sharper with increasing austempering time, indicative of the variation of lattice distortion. Meanwhile, retained austenite peaks are visible in most cases. However, the as-quenched sample does not present the maximum intensities in the austenite peaks, which would suggest increased austenite following the austempering treatments. 


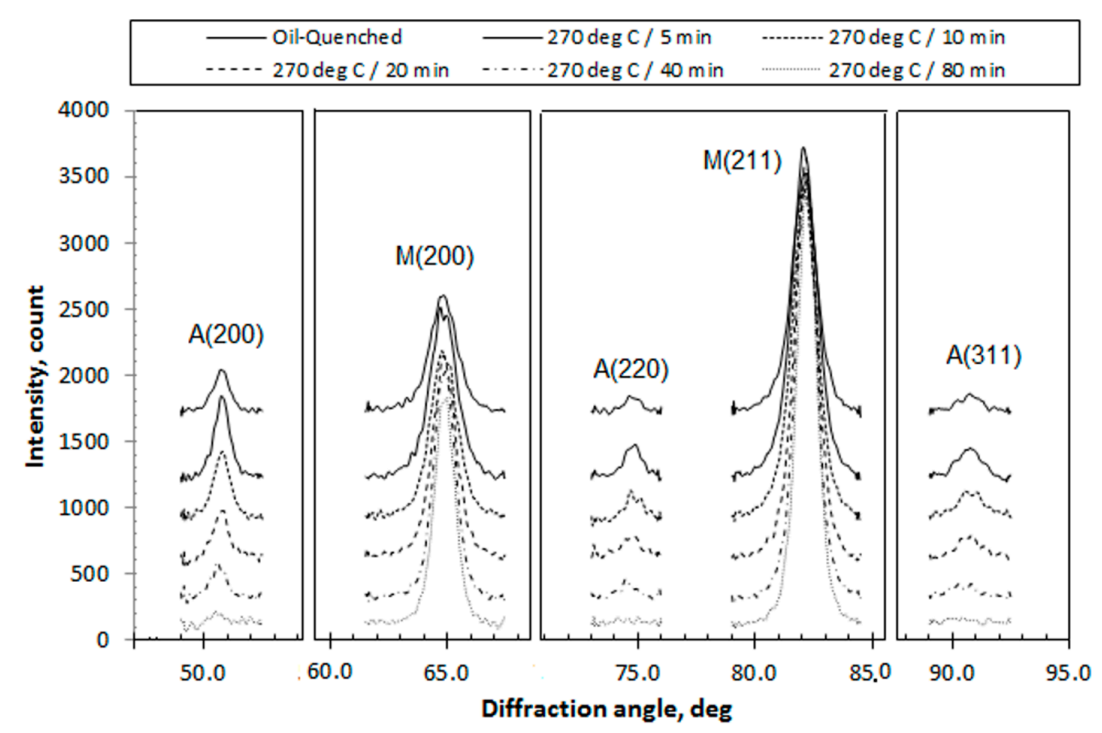

Figure 6. X-ray diffraction (XRD) peaks of the retained austenite and martensitic/bainitic ferrite phases.

Valuable results on the microstructure characteristics have been obtained from the quantitative analyses of these diffraction patterns, including the volume fraction, carbon content and micro-strain of retained austenite and two types of ferritic sub-phases. Detailed consideration of the ferritic sub-phases can be found in a recent publication [31], namely, that the mixture of martensite and bainite structure have been treated as two martensitic sub-phases ( $\mathrm{M}_{\text {plate }}$ and $\left.\mathrm{M}_{\text {lath }}\right)$ of different tetragonal ratios; although, a limitation of the method was that it was not capable of separating the austemperin-formed bainite and the quenching-formed martensites. Figure 7 shows an example of separation of the ferrite diffraction peak $(200)_{\alpha}$ as four sub-peaks using the Gaussian peak-fitting technique, where peaks 1 and 2 represent the $M_{\text {plate }}$ diffractions and peaks 3 and 4 represent the $M_{\text {lath }}$ diffractions. Then the integrated intensity, peak position and FWHM value of each sub-peak can be measured to calculate the crystalline characteristics. The results are shown in Figure 8.

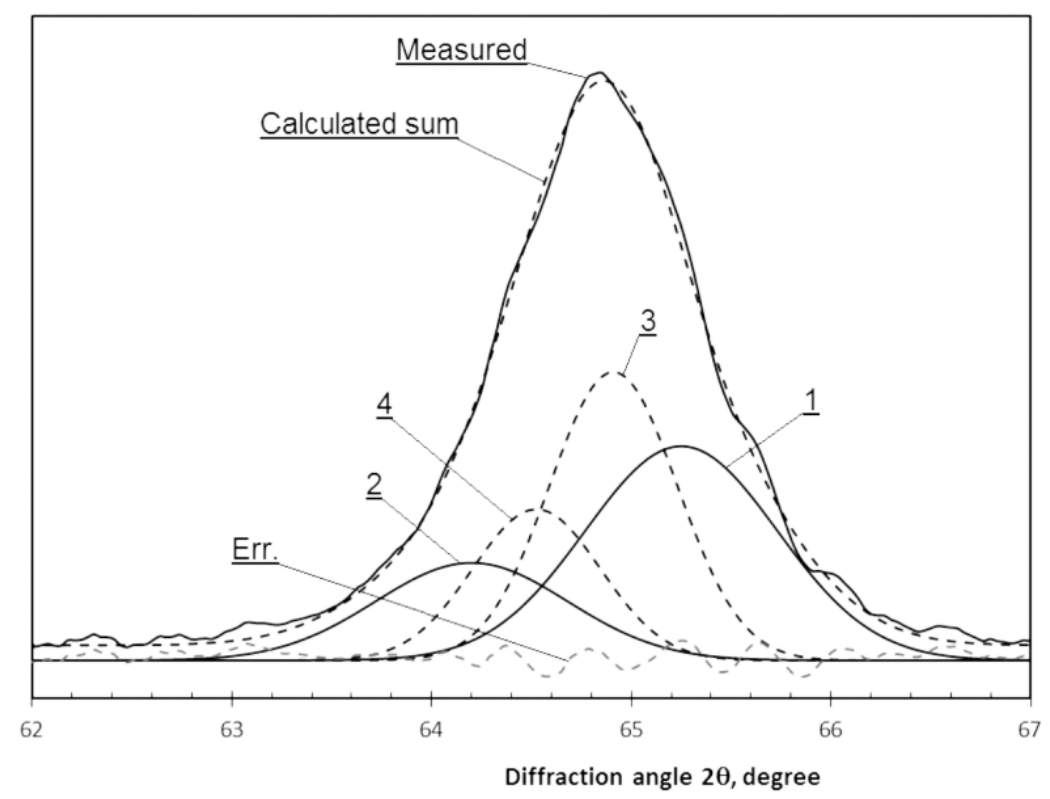

Figure 7. Multiple Gaussian peaking fitting to separate the $(200)_{\alpha}$ peak as four sub-peaks of the $\mathrm{M}_{\text {plate }}$ and $\mathrm{M}_{\text {lath }}$ sub-phases as labelled: 1-(200) of $\mathrm{M}_{\text {plate, }}$-(002) of $\mathrm{M}_{\text {plate, }}$ 3-(200) of $\mathrm{M}_{\text {lath}}$, and 4-(002) of $\mathrm{M}_{\text {lath }}$. 


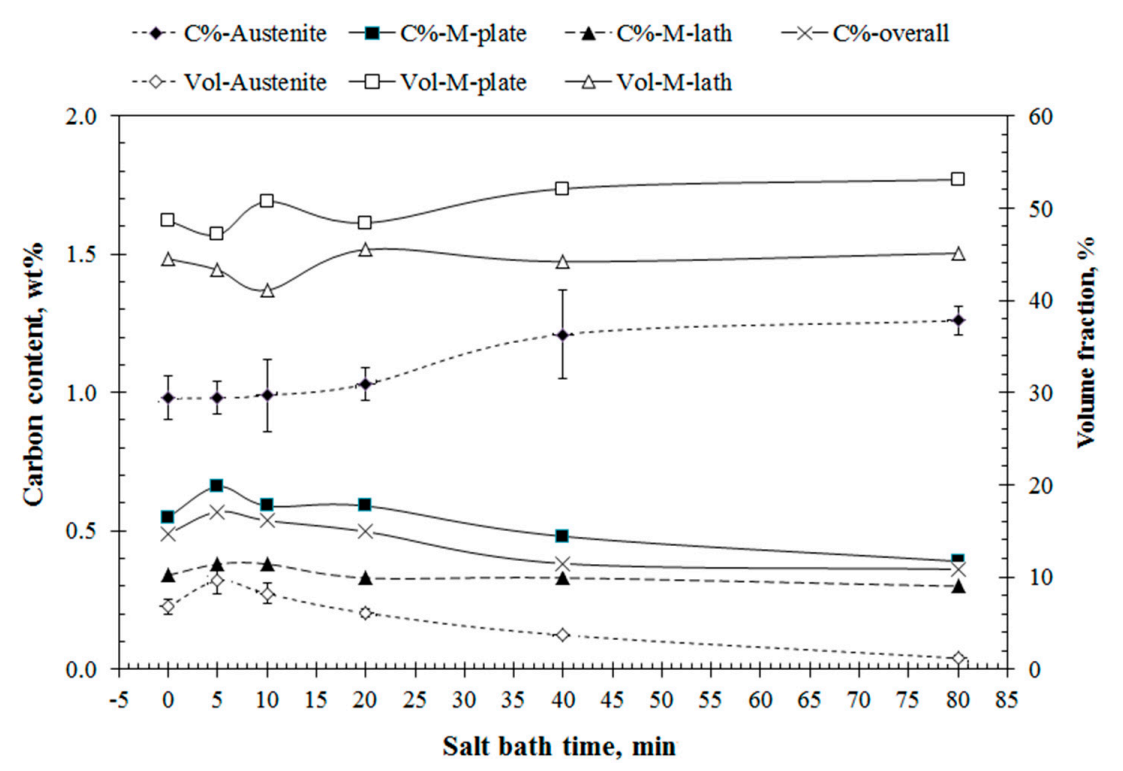

Figure 8. Quantified results of XRD analyses: Effect of austempering time on the volume fraction, carbon content and lattice strain of the matrix phases.

Figure 8 illustrates the effect of austempering time on the variation of volume fraction and carbon concentration of the three matrix constituents. In general, the ferritic $\mathrm{M}_{\text {plate }}$ and $\mathrm{M}_{\text {lath }}$ sub-phases account for the majority of volume fraction, whereas the retained austenite is much less. The $\mathrm{M}_{\text {plate }}$ sub-phase has a higher carbon concentration and a larger lattice strain (see Figure 1) than the $\mathrm{M}_{\text {lath }}$ sub-phase. In addition, retained austenite shows enriched carbon content, as compared to the ferritic phases.

It is interesting to note the differences between the oil-quenched and short-time austempered samples. Firstly, the $5 \mathrm{~min}$ austempering pre-treatment resulted in slightly increased volume fractions of retained austenite from $6.8 \%$ to $9.6 \%$, while its carbon concentration remained unchanged at $0.98 \%$. Accordingly, the volume fractions of the $\mathrm{M}_{\text {plate }}$ and $\mathrm{M}_{\text {lath }}$ decreased slightly. In addition, the $\mathrm{M}_{\text {plate }}$ of the austempered sample shows higher carbon concentration $(0.57 \%)$ than the oil-quenched counterpart $(0.49 \%)$ along with increased lattice strain from $0.79 \%$ to $0.84 \%$. The less carbon concentration in the oil-quenched $\mathrm{M}_{\text {plate }}$ may be related to simultaneous carbide precipitation as suggested in the SEM observation (e.g., Figure 3c). A similar difference in the carbon concentration is also found in the $\mathrm{M}_{\text {lath }}$ sub-phase. The $10 \mathrm{~min}$ austempered sample also shows superior amount of retained austenite as compared to the oil-quenched sample as well as slightly increased ferrite carbon concentrations, although not as strong as in the 5 min austempered sample.

The austempering time shows pronounced influence on the structural properties. A high carbon content of $0.59-0.66 \%$ was retained in the $\mathrm{M}_{\text {plate }}$ when the sample was austempered for less than $20 \mathrm{~min}$. Then it decreased to $0.48 \%$ and $0.39 \%$ respectively, when the bath time was increased to 40 and $80 \mathrm{~min}$. For the $\mathrm{M}_{\text {lath }}$, its carbon content decreased from $0.38 \%$ to $0.30 \%$ when the austempering time was increased from 5 to $80 \mathrm{~min}$, which is relatively negligible as compared to the $\mathrm{M}_{\text {plate }}$. The more pronounced decarbonisation in the $\mathrm{M}_{\text {plate }}$ is consistent with the SEM observations that carbide precipitates appeared preferentially in the $\mathrm{M}_{\text {plate }}$ grains. Meanwhile, the volume fraction of retained austenite decreased from $6.1 \%$ to $1.2 \%$ when the austempering time was increased from 20 to $80 \mathrm{~min}$, accompanying continuous enrichment in its carbon concentration from $1.03 \%$ to $1.26 \%$. The results suggest partial decomposition of the austenite and continuous carbon partitioning between the austenite and ferrite. Finally, the overall carbon content illustrated in Figure 8 stands for the average carbon content in the iron-based matrix, including the martensitic and bainitic ferrites and retained austenite, except for carbide precipitates. The overall carbon content of matrix starts decreasing 
when the austempering time was increased from 20 to $40 \mathrm{~min}$, which is consistent to the pronounced carbide precipitation.

\section{Discussion}

\subsection{Hardening Mechanism in Austempering Treatment}

The results presented reveal that, a short-term isothermal bainitic transformation can be introduced prior to the continuous-cooling martensite transformation, which would favour both the refinement of the overall bainitic/martensitic ferrite microstructure and the maximised hardening. Such austempering has served as a replacement of conventional oil-quenching, promising ultrahigh strength properties, as shown in our recent work [28].

Regarding the hardening mechanisms, our finding that short-time austempering treatment promotes grain refining is consistent with the results of others. For example, previous TEM observations have revealed that, oil-quenched $300 \mathrm{M}$ steel showed relatively lengthy martensitic laths in contrast to the isothermally transformed bainitic laths of the same material [36]. However, our findings differ from the mechanisms suggested by those previous studies, in which the martensite grain refining was attributed to partitioning of austenite grains by pre-formed bainitic ferrite [3,11-15,37]. If such a mechanism were true in the current experiments, the steel would have shown lengthy bainitic ferrite laths or plates to partition the austenite grains. In fact, such length bainitic needles were not observed, as shown in Figures 3b,d, 4a and 5a. Instead, we found that grain coarsening took place when the austempering time exceeded $20 \mathrm{~min}$. The findings suggest that martensite refining took place prior to the growth of the bainitic laths.

Instead of the partitioning mechanism, the current work is more likely explained by the mechanism of carbon spinodal decomposition, in other words, carbon re-distribution in the under-cooled austenite. In this isothermal period, atomic and electronic interactions might happen between the carbon atoms and the metal atoms in the austenite lattice, which results in the heterogeneous distribution of carbon atoms in the austenite lattice. Consequently nanoscale body-centre cubic embryos could nuclear in the carbon-depleting regions of the parent austenite. The spinodal model was proposed by Kang and his group when spinodal decomposition of carbon-rich clusters was evidenced in their TEM investigation [32,33]. In their publications, the formation of carbide-free bainitic ferrite was described as a series of phase transformation sub-processes starting from the localised clustering or spinodal decomposition within under-cooled austenite. The spinodal decomposition required carbon atoms to undergo only short-range motion, which is time-dependent and would be available at the austempering temperature. Then the spinodal decomposition was proposed to trigger the formation of bainite embryos in the resultant carbon-depleted regions, before the embryo growth under the displacive model. The embryo growth proceeds along with simultaneous carbon diffusion across the austenite-ferrite interface to enhance carbon enrichment in the adjacent austenite. Then, subsequent nucleation and growth of carbide precipitates take place in the bainitic ferrite $[38,39]$. Several other groups have also confirmed the carbon heterogeneity in super-cooled austenite and martensitic/bainitic ferrite [22,26,40-42].

As a result of the spinodal decomposition, the carbon distribution would be more heterogeneous in nano-scale, so that a large number of ferrite nuclei could be generated in the carbon-depletion domains. For the samples being austempered for only 5 min the SEM observations did not reveal any bainitic ferrite, as shown in Figure 3b,d. Instead, the under-cooled austenite transformed to martensite in the subsequent cooling. The resultant refining can be explained by the increased nucleation sites of the martensites as a sequence of the heterogeneous distribution of carbon.

In addition to these, our results suggest that the role of carbon in strengthening can be described in two aspects. In the first, the short-term austempering treatment did not lead to carbide precipitation in the bainitic ferrite. Consequently, the bainitic and martensitic ferrite still remained a super-saturated carbon concentration, leading to the maximum solute hardening. Secondly, the 
combined XRD and Gaussian multiple peak-fitting analyses have indicated different tetragonal ratios and carbon concentrations of the lath- and plate-shape ferrites, both remaining at high levels of carbon supersaturation, as compared to the oil-quenched martensites. The carbon supersaturation is known to ensure a high level of solute hardening of the martensites.

\subsection{Effect of Austempering Time on the Resultant Microstructure}

Moreover, the austempering treatment has been found to lead to microstructure evolution in three aspects, namely, re-distribution of carbon, coarsening of bainitic ferrite, and continuous decomposition of retained austenite.

Firstly, the carbon re-distribution includes a continuous decrease of carbon supersaturation in the ferritic matrix, through precipitation and growth of dispersive carbide particles, as shown in Figure 5. More precisely, the carbon re-distribution took place preferentially in the high-carbon plate-shape bainitic ferrite grains, whereas the low-carbon lath-shape ferrite almost remained at the same carbon concentration, as shown in Figure 8. Meanwhile, carbon atoms in the ferrite continued immigration to the adjacent austenite to make the latter even richer in carbon. The increased carbon enrichment has been confirmed in the XRD analysis, as shown in Figure 8. Such heterogeneous distribution of carbon in martensitic/bainitic microstructure has been confirmed by other sophisticated analyses. In a more recent paper, atomic probe tomography of a nanobainitic steel revealed the heterogeneous carbon content in bainitic ferrite, where the ferrite is in close vicinity of the ferrite-austenite interface, showed low carbon concentration as compared to the remarkably high carbon concentration in the core ferrite region [43].

Secondly, the longitudinal and transverse dimensions of the bainitic ferrite grains increased with the austempering time. The current experiment results provide evidences on the time-dependent transformation of bainite structure. It is well known that there has long been a controversy on the displacive or shear model and diffusive model of bainite transformation as documented in the literature, e.g., a latest review paper [44]. In the present case, we believe the growth of bainitic ferrite laths was dominated, or at least strongly influenced, by the diffusion of carbon.

In the last, the quantity of retained austenite continued to decrease, and became almost non-detectable when the austempering was $80 \mathrm{~min}$.

Furthermore, we also noticed in the current research that dendritic segregations initiated in steel casting still show significant influence on the chemical homogeneity of the steel even after several rounds of thermal processing. This has been evidenced by the heterogeneous distributions of both the lath and plate martensites in oil-quenched samples and the bainitic and martensitic sub-structures. The segregation would have happened firstly on the substitutional elements, such as $\mathrm{Mn}, \mathrm{Cr}, \mathrm{Ni}$ and $\mathrm{Mo}$. Carbon is known to be attractive to carbide-forming elements and repulsive to non-carbide-forming elements $[45,46]$. As a result, the heterogeneity of the substitutional elements also influences the distribution of carbon, and consequently may have influenced the transformation kinetics, from the spinodal decomposition of under-cooled austenite to the carbon-diffusion affected ferrite growth. More research attention will be given to this issue later.

\section{Conclusions}

Short-time austempering treatment of the $56 \mathrm{NiCrMoV7}$ spring steel in a salt-bath time of 5 to $10 \mathrm{~min}$ resulted in the maximum hardness values being equivalent to the oil-quenched sample; meanwhile, the resultant microstructure comprised a mixture of fine martensitic and bainitic ferrites and retained austenite. When the austempering time was increased from 20 to $80 \mathrm{~min}$, progressive decrease in the hardness was associated with the evolution of the microstructure, featured by bainitic ferrite coarsening, carbide precipitating inside high-carbon bainitic ferrite and its subsequent decarbonisation.

Carbon partitioning showed significant influence on the hardening in several aspects: 
(1) Soaking super-cooled austenite at a temperature above its $M_{s}$ temperature favours the refining of the transformed ferritic microstructure, which may be related to short-range spinodal decomposition of carbon in the incubation period;

(2) The best hardening state is obtained prior to remarkable carbide precipitation, i.e., when most carbon atoms remain supersaturated in the bct-structured ferrite;

(3) Following longer austempering time, the bainitic ferrite becomes increasingly decarbonised through continuous carbon clustering and carbide precipitation.

Acknowledgments: The authors acknowledge that the research was partially sponsored by Innovate UK (formerly Technology Strategy Board) of the UK government through Smart Award No. 720113. Tinsley Bridge Limited is acknowledged for providing the sample steel and colaboration in the Smart Award project.

Author Contributions: Matthew Kitchen participated in the heat treatments, sample preparation, and SEM analyses; Shahriar Abubakri participated in sample preparation, OPM, hardness testing, and XRD experiments; Quanshun Luo led the research, participated in the heat treatments, X-ray diffraction quantification and SEM, and wrote the paper.

Conflicts of Interest: The authors declare no conflict of interest.

\section{References}

1. Li, Z.; He, Z.Q.; Jin, J.J.; Zhong, P. Development of Aeronautical Ultra-High Strength Steels; National Defence Industry Press: Beijing, China, 2012.

2. Krauss, G. Deformation and fracture in martensitic carbon steels tempered at low temperatures. Metall. Mater. Trans. B 2001, 32, 205-221. [CrossRef]

3. Tomita, Y. Development of fracture toughness of ultrahigh strength, medium carbon, low alloy steels for aerospace applications. Int. Mater. Rev. 2000, 45, 27-37. [CrossRef]

4. Caballero, F.G.; Bhadeshia, H.K.D.H.; Mawell, K.J.A.; Jones, G.D.; Brown, P. Design of novel high strength bainitic steels. Mater. Sci. Technol. 2001, 17, 512-522. [CrossRef]

5. Caballero, F.G.; Bhadeshia, H.K.D.H.; Mawell, K.J.A.; Jones, D.G.; Brown, P. Very strong low temperature bainite. Mater. Sci. Technol. 2002, 18, 279-284. [CrossRef]

6. Caballero, F.G.; Bhadeshia, H.K.D.H. Very strong bainite. Curr. Opin. Solid State Mater. Sci. 2004, 8, $251-257$. [CrossRef]

7. Garcia-Mateo, C.; Caballero, F.G. Ultra high strength bainitic steels. ISIJ Int. 2005, 45, 1736-1740. [CrossRef]

8. Kang, M.K.; Zhu, M.; Zhang, M.X. Mechanism of bainite nucleation in steel, iron and copper alloys. J. Mater. Sci. Technol. 2005, 21, 437-444.

9. Kang, M.K.; Zhu, M. Stabilization of austenite in quenched alloy steels. Acta Metall. Sin. 2005, 41, 673-679.

10. Wang, T.S.; Li, X.Y.; Zhang, F.C.; Zheng, Y.Z. Microstructures and mechanical properties of 60Si2CrVA steel by isothermal transformation at low temperature. Mater. Sci. Eng. 2006, 438-440, 1124-1127. [CrossRef]

11. Malakondaiah, G.; Srinivas, M.; Rao, P.R. Ultrahigh-strength low-alloy steels with enhanced fracture toughness. Prog. Mater. Sci. 1997, 42, 209-242. [CrossRef]

12. Rao, T.V.L.N.; Dikshit, S.N.; Malakondaiah, G.; Rap, P.R. On mixed upper bainite-martensite in an AISI 4330 steel exhibiting an uncommonly improved strength-toughness combination. Scr. Metall. Mater. 1990, 24, 1323-1328. [CrossRef]

13. Park, K.T.; Kwon, H.J. Interpretation of the strengthening of steel with lower bainite and martensite mixed microstructure. Met. Mater. Int. 2001, 7, 95-99. [CrossRef]

14. Abbaszadeh, K.; Kheirandish, S.; Saghafian, H. The effect of lower bainite volume fraction on tensile and impact properties of D6AC medium carbon low alloy ultrahigh strength steel. Iran. J. Mater. Sci. Eng. 2010, 7,31-38.

15. Sharma, S.; Sangal, S.; Mondal, K. Development of new high-strength carbide-free bainitic steels. Metall. Mater. Trans. A 2011, 42, 3921-3923. [CrossRef]

16. Safi, S.M.; Givi, M.K.B. A new step heat treatment for steel AISI 4340. Met. Sci. Heat Treat. 2014, 56, 79-81. [CrossRef]

17. Lan, H.F.; Du, L.X.; Zhou, N.; Liu, X.H. Effect of austempering route on microstructural characterization of nanobainitic steel. Acta Metall. Sin. 2014, 27, 19-26. [CrossRef] 
18. Young, C.H.; Bhadeshia, H.K.D.H. Strength of mixtures of bainite and martensite. Mater. Sci. Technol. 1994, 10, 209-214. [CrossRef]

19. Kang, M.K.; Ai, Y.L.; Zhang, M.X.; Yang, Y.Q.; Zhu, M.; Chen, Y. Carbon content of bainite ferrite in 40CrMnSiMoV steel. Mater. Chem. Phys. 2009, 118, 438-441. [CrossRef]

20. Garcia-Mateo, C.; Jimenez, J.A.; Yen, H.W.; Miller, M.K.; Morales-Rivas, L.; Kuntz, M.; Ringer, S.P.; Yang, J.R.; Caballero, F.G. Low temperature bainitic ferrite: Evidence of carbon super-saturation and tetragonality. Acta Mater. 2015, 91, 162-173. [CrossRef]

21. Garcia-Mateo, C.; Caballero, F.G.; Miller, M.K.; Jimenez, J.A. On measurement of carbon content in retained austenite in a nanostructured bainitic steel. J. Mater. Sci. 2012, 57, 1004-1010. [CrossRef]

22. Speer, J.G.; Matlock, D.K.; De Cooman, B.C.; Schroth, J.G. Carbon partitioning into austenite after martensite transformation. Acta Mater. 2003, 51, 2611-2622. [CrossRef]

23. Edmonds, D.V.; He, K.; Rizzo, F.C.; De Cooman, B.C.; Matlock, D.K.; Speer, J.G. Quenching and partitioning martensite-A novel steel heat treatment. Mater. Sci. Eng. A 2006, 438-440, 25-34. [CrossRef]

24. Rong, Y. Advanced Q-P-T steels with ultrahigh strength-high ductility. Acta Metall. Sin. 2011, 47, 1483-1489.

25. Li, H.Y.; Lu, X.W.; Li, W.J.; Jin, X.J. Microstructure and mechanical properties of an ultrahigh-strength 40SiMnNiCr steel during the on-step quenching and partitioning process. Metall. Mater. Trans. A 2010, 41, 1284-1300. [CrossRef]

26. Hsu, T.Y. Carbon diffusion and kinetics during the lath martensite formation. J. Phys. IV Fr. 1995, 5, C8-351-C8-354.

27. Luo, Q.; Kitchen, M.; Patel, V.; Magowan, S. Carbon partitioning and structure evolution in the hardening treatments of high strength steel. In Proceedings of the 20th Congress of International Federation for Heat Treatment and Surface Engineering, Beijing, China, 23-25 October 2012; pp. 111-117.

28. Luo, Q.; Kitchen, M.; Patel, V.; Filleul, M.; Owens, D. Partial-isothermally-treated low alloy ultrahigh strength steel with martensitic/bainitic microstructure. In HSLA Steels 2015, Microalloying 2015 \& Offshore Engineering Steels 2015; John Wiley \& Sons: Hoboken, NJ, USA, 2015; pp. 433-438.

29. Garg, A.; McNelley, T.R. Estimation of martensite carbon content in as-quenched AISI 52100 steel by X-ray diffraction. Mater. Lett. 1986, 4, 214-218. [CrossRef]

30. Abbaschian, R.; Abbeschian, L. Physical Metallurgy Principles, Reed-Hill RE, 4th ed.; Cengage Learning: Stanford, CA, USA, 1994.

31. Luo, Q. A new XRD method to quantify plate and lath martensites of hardened medium-carbon steel. J. Mater. Eng. Perform. 2016, 25, 2170-2179. [CrossRef]

32. Kang, M.K.; Yang, Y.Q.; Wei, Q.M.; Yang, Q.M.; Meng, X.K. On the prebainitic phenomenon in some alloys. Metall. Mater. Trans. A 1994, 25, 1941-1946. [CrossRef]

33. Wu, X.L.; Zhang, X.Y.; Meng, X.K.; Kang, M.K.; Yang, Y.Q. Formation of carbon-poor regions during pre-bainitic transformation. Mater. Lett. 1995, 22, 141-144. [CrossRef]

34. Khan, S.A.; Bhadeshia, H.K.D.H. The bainite transformation in chemically heterogeneous 300M high-strength steel. Metall. Trans. A 1990, 21, 859-875. [CrossRef]

35. Zhang, X.Y.; Kang, M.K.; Wu, X.L.; Chen, D.M.; Han, D. Study on several carbide variants in the low bainite of 65Si2MnWA steel by TEM. Chin. Sci. Bull. 1994, 39, 1583-1584.

36. Luo, C.P.; Liu, J. Crystallography of lath martensite and lower bainite in alloy steels. Mater. Sci. Eng. A 2006, 438-440, 149-152. [CrossRef]

37. Yang, F.B.; Bai, B.Z.; Liu, D.Y.; Chang, K.D.; Wei, D.Y.; Fang, H.S. Microstructure and properties of a carbide-free bainite/martensite ultrahigh strength steel. Acta Metall. Sin. 2004, 40, 296-300.

38. Kang, M.K.; Yang, Y.Q.; Zhang, X.Y.; Sun, J.L.; Jia, F.S.; Wu, X.L. Bainitic transformation in silicon-containing steels. Acta Metall. Sin. 1996, 32, 897-903.

39. Kang, M.K.; Zhang, M.X.; Zhu, M. In-situ observation of bainite growth during isothermal holding. Acta Mater. 2006, 54, 2121-2129. [CrossRef]

40. Hsu, T.Y.; Li, X.M. Diffusion of carbon during the formation of low-carbon martensite. Scr. Metall. 1983, 17, 1285-1288. [CrossRef]

41. Lawrynowicz, Z. Carbon partitioning during bainite transformation in low alloy steels. Mater. Sci. Technol. 2002, 18, 1322-1324. [CrossRef]

42. Caballero, F.G.; Miller, M.K.; Clarke, A.J.; Garcia-Mateo, C. Examination of carbon partitioning into austenite during tempering of bainite. Scr. Mater. 2010, 63, 442-445. [CrossRef] 
43. Timokhina, I.B.; Beladi, H.; Xiong, X.Y.; Adachi, Y.; Hodgson, P.D. Nanoscale microstructure characterization of a nanobainitic steel. Acta Mater. 2011, 59, 5511-5522. [CrossRef]

44. Fielding, L.C.D. The bainite controversy. Mater. Sci. Technol. 2013, 29, 383-399. [CrossRef]

45. Gavriljuk, V.G.; Shanina, B.D.; Berns, H. On the correlation between electron structure and short range atomic order in iron-based alloys. Acta Mater. 2000, 48, 3879-3893. [CrossRef]

46. Shanint, B.D.; Gavriljuk, V.G.; Konchits, A.A.; Kolesnik, S.P. The influence of substitutional atoms upon the electron structure of the iron-based transition metal alloys. J. Phys. 1998, 10, 1825-1838. 